\title{
Big Plans, Poor Execution: The Importance of Governmental Managerial Innovation to Health Care Reform
}

\author{
Sachin H. Jain, , MD, $M B A^{1,2,3}$, Brian W. Powers, , $A B^{7}$, and Darshak Sanghavi, , $M D^{4}$ \\ ${ }^{1}$ Harvard Medical School, Boston, MA, USA; ${ }^{B}$ Boston-VA Medical Center, Boston, MA, USA; ${ }^{3}$ Merck and Co., Inc., Boston, MA, USA; 'Brookings \\ Institution, Washington, DC, USA.
}

J Gen Intern Med 30(4):395-7

DOI: $10.1007 / \mathrm{s} 11606-014-3083-7$

(c) Society of General Internal Medicine 2014

\section{INTRODUCTION}

The Affordable Care Act (ACA)'s implementation failuresincluding the launch of healthcare.gov and delays of several key provisions of the legislation - have threatened continued support for the law. At the core of the public's misgivings is trust in whether government agencies can effectively implement programs of importance on massive scale. The ACA rollout has exposed deep flaws in the ways in which federal agencies manage the implementation of legislative efforts. For these reasons, we strongly believe that health policy reform must occur alongside innovation and reform of the managerial processes of the Department of Health and Human Services (HHS) and its constituent agencies. In this paper we draw on experiences implementing significant health care policy legislation - the HITECH Act and the ACA - to explore the fundamental management challenges that have hampered the implementation of the ACA, and threaten the future viability of government-led health care reform.

\section{PROCUREMENT REFORM}

Implementing new legislation requires considerable infrastructure investments and the development of new operational capabilities. This often requires that the government contract with outside vendors for various goods and services - a process known as government procurement. In order to purchase an item or service - from desk chairs to multi-million dollar infrastructure projects - the government must adhere to a formalized procurement process.

The troubled launch of healthcare.gov brought into focus several entrenched problems with the federal government's procurement process. The first is the overly burdensome and bureaucratic process of soliciting, vetting, and awarding contracts. Initially designed as safeguards against kickbacks, regulations have evolved to the point where contracts are awarded to firms with the most experience in navigating the federal procurement process, rather than those with the most experience and skills in the content area. And though the firms that

Published online November 11, 2014 have mastered the procurement process certainly benefit from the status quo, they too stand to gain from procurement reform; fewer set-asides, greater accountability, and pay-forperformance in the procurement process benefits everyone in the marketplace.

Second, the operational units within each agency responsible for managing contracts and implementing reforms are too far removed from the procurement process. Procurement for all HHS contracts is handled by a centralized office, under the oversight of a panel that lacks any representation or input from the unit originating the proposal. Agency staff often have no opportunity to discuss or collaborate with potential clients until the contract has been awarded. This is in stark contrast to the intimate discussions and negotiations that are commonplace in the private sector, even among large corporations. For the development of healthcare.gov, 55 separate contractors were responsible for developing the site, with few opportunities for collaboration and little oversight. When the government entered salvage mode and relied on a tactical group of contractors handpicked from the private sector and operating outside the federal contracting process, a small team of several dozen largely fixed the websites problems within six weeks. ${ }^{1}$

Finally, the rigidity encountered early in the contracting process is mirrored in constraints around termination. When a federal contract is awarded to a government contractor, it is difficult to change contractors if it becomes apparent that the contractor is not fulfilling the obligations of the contract. Unlike in the private sector, when the contract can be terminated at will, the contractor can engage in a lengthy appeals process that prevents the agency from advancing the project.

There are several near-term policy options that could remove many of these barriers. For example, the federal government is already working on streamlining the bidding process to remove some of the technical challenges and bureaucratic hurdles associated with submitting bids for government projects. Another mechanism to encourage bids from smaller, specialized firms not seasoned in the procurement process is to circumvent the traditional procurement infrastructure for smaller projects. Currently, there is a streamlined bidding and review process for contracts under $\$ 150,000$. Raising this bar-termed the small acquisition threshold —above $\$ 150,000$ could introduce much needed competition and technical expertise.

The selection and vetting process could be improved by including representatives from sponsoring units on review 
panels, especially when the contracts are for products and services outside the traditional bounds of expertise for HHS' procurement office. Finally, termination procedures could be amended to require concrete, staged deliverables, and early windows of review (e.g., 90 days) for all new contracts to allow for expedited termination if contractors are not performing adequately.

Depending on the scope of change desired, each of these reforms could be enacted as a permanent alteration to the federal procurement process, or as case-by-case waivers written into specific legislation for initiatives that are of critical significance to the country.

\section{HUMAN RESOURCES REFORM}

The successful implementation and sustained management of complex legislation requires recruiting and retaining a diverse and expert workforce. Unfortunately, federal agencies often struggle to attract and retain appropriate, competitive talent. Implementation is notoriously demanding and draining work. This is compounded by the fact that most federal agencies offer few opportunities for advancement, and talented individuals can obtain significantly higher salaries in the private sector. When the Partnership for Public Service (PPS) surveyed federal hiring managers regarding their experiences with recruiting and retaining talented professionals, respondents identified "pay in comparison to the private sector" as the top deterrent. Nearly $60 \%$ also identified "limited opportunities for professional advancement" as a chief concern. ${ }^{2}$ Rapid turnover and vacant positions make it difficult to implement initiatives that require continuity, and hamper the viability of reform efforts.

While we believe that federal salaries should be managed carefully, strengthening the implementation workforce will require more competitive pay. Leadership for many of the ACA's programs require seasoned health care leaders, often with medical or other advanced degrees. These requirements simply do not align with traditional federal pay scales. Federal wages tend to track private sector wages up through masterslevel degrees, but studies show that federal employees with a doctorate or professional degree earn on average $25 \%$ less per hour than comparable workers in the private sector. ${ }^{3}$ Modifications or waivers to the standard general services pay scale could be written into specific legislations, or HHS' Chief Human Capital Officer could be given the authority to authorize higher salaries for critical initiatives and personnel.

Early career fellowships, tuition reimbursement, and loan repayment programs are additional strategies that could be used to recruit and a talented workforce. Such programs are already in place for physician-scientists and members of the Public Health Services. Expanding these initiatives at HHS would attract students from schools of public policy, business, public health, and medicine interested in careers in public service. Similarly, tuition repayment programs would offer existing employees important opportunities for career advancement, with the assurances that their talents would continue to support the efforts of the sponsoring agency.

It is equally important to explore strategies beyond compensation and benefits. It is well documented that the factors impacting employee recruitment and retention extend far beyond money. ${ }^{4}$ Here, HHS should learn from best practices in the human resources community. Federal agencies could offer leadership training programs for selected individuals, and establish more structured mentorship programs. Several agencies and offices, including the Office of Personnel Management, the Department of State, USAID, and the Environmental Protection Agency, have adopted formal mentoring programs. ${ }^{5}$ While HHS has such a program, it is structured with a one year duration, potentially limiting effectiveness. ${ }^{6}$ HHS should also explore ways to allow for more mobility within government. Agencies are increasingly collaborating with each other, Congress, and the White House. This opens up natural opportunities for lateral movement that should be formalized and encouraged. Finally, the federal government could look to the private sector and to other countries for ideas on how to attract and retain top talent. Tried-and-true policies include the promise of healthy work-life balance, affordable child-care, and plentiful vacation.

\section{CONCLUSION}

Implementation is the ultimate test of any legislative effort- $-\mathrm{a}$ difficult reality currently facing the supporters and architects of the ACA. Challenges with the ACA have uncovered fundamental flaws in the federal government's managerial structures for executing complex legislative agendas. If we expect our federal health agencies to take a frontline role in reforming health care, so too must we pay attention to reforming these institutions.

Funding/Support: None.

Other disclosures: The authors have no disclosure related to the content of this manuscript.

Disclaimers: The views expressed in this article represent the authors' views and not the views or policies of their respective affiliated institutions.

Corresponding Author: Sachin H. Jain, , MD, MBA; Harvard Medical School, 65 East India Row, Boston, MA 02110, USA (e-mail: shjain@post.harvard.edu).

\section{REFERENCES}

1. Brill S. Obama's Trauma Team. Time 10 March 2014.

2. Brykczynski B, Flattau PE, Nek R. Attracting and Retaining Science and Engineering Talent in the Federal Government: A Workshop Summary. 2013. Washington, DC: IDA Science and Technology Policy Institute

3. Congressional Budget Office. Comparing the Compensation of Federal and Private-Sector Employees. 2012. Washington, DC: Congressional Budget Office 
4. Llorens JC, Stazyk EC. How Important Are Competitive Wages? Exploring the Impact of Relative Wage Rates on Employee Turnover in State Government. Review of Public Personnel Administration. 2011;31(2):111127.
5. Office of Personnel Management. http://www.opm.gov/wiki/training/ Mentoring-and-Coaching.ashx

6. Department of Health and Human Services. https://mentoring.hhs.gov/ index.aspx 